\title{
Tactile discrimination following analgesia-producing brainstem stimulation in the rat
}

\author{
GABRIEL P. FROMMER \\ Indiana University, Bloomington, Indiana
}

\begin{abstract}
Female albino rats were trained on a standard tactile discrimination and implanted with subcutaneous heating coils and stimulating electrodes aimed at analgesia-producing sites in brainstem. The effectiveness of brainstem stimulation in producing analgesia was assessed by measuring increase in latency of face wiping elicited by heating the subcutaneous coils about 30 sec after brain stimulation. Stimulation was then introduced $15 \mathrm{sec}$ before or at the start of one of the six daily massed tactile discrimination trials. Errors and response latencies on the test discrimination trials were compared with errors and latencies on the immediately preceding and subsequent trials. Eight rats increased latency of face wiping and had electrodes in dorsal periaqueductal gray (PAG). Their performance on the tactile discrimination was disrupted on trials immediately following stimulation. Four other rats also showed increased face-wiping latencies but had electrodes outside dorsal PAG. Their discrimination performance was less consistently affected by brain stimulation. The remaining seven rats did not show increased face-wiping latencies. Their electrodes were also outside dorsal PAG, and they showed latency increases only when stimulation occurred at the start of test trials. These data indicate that analgesia-producing brainstem stimulation can affect performance on a tactile discrimination task as well as on the reaction to noxious stimulation.
\end{abstract}

Electrical stimulation at various locations in the brainstem produces a depression in response to noxious stimuli (analgesia) which often outlasts the duration of the stimulation by seconds or minutes (see Basbaum \& Fields, 1978, and Watkins \& Mayer, 1982, for recent reviews). The phenomenon has been demonstrated in several species, including humans (Hosobuchi, Adams, \& Linchitz, 1977; Richardson \& Akil, 1977), cats (Liebeskind, Guilbaud, Besson, \& Oliveras, 1973; Oliveras, Besson, Guilbaud, \& Liebeskind, 1974), and rats (Mayer, Wolfe, Akil, Carder, \& Liebeskind, 1971; Morrow \& Casey, 1976; Reynolds, 1969; Rhodes \& Liebeskind, 1978). Stimulation is effective at a variety of sites. They include periaqueductal gray (PAG), especially the ventromedial part in the caudal midbrain (Mayer et al., 1971; Morrow \& Casey, 1976; Reynolds, 1969), ventral tegmentum (Mayer et al., 1971), caudal diencephalic PAG (Mayer \& Liebeskind, 1974; Richardson \& Akil, 1977; Rhodes \& Liebeskind, 1978), posterior and medial thalamus and hypothalamus (Rhodes \& Liebeskind, 1978), and lateral

This research was supported by NIH Grants GM29254 and BRSG S07 RR07031. I thank B. Abrams, B. Briner, P. Stern, and P. Whang for assistance in collecting behavioral data, R. Myers for preparation of the histological material, and two anonymous reviewers for helpful suggestions. A preliminary report on this research was presented at the annual meeting of the Midwestern Psychological Association, Chicago, May 1984.

The author's mailing address is: Department of Psychology, Indiana University, Bloomington, IN 47405. hypothalamus (Balagura \& Ralph, 1973; Cox \& Valenstein, 1965; Rose, 1974).

The main thrust of the research on this phenomenon has been to identify the anatomical loci at which analgesia can be induced, the pathways that mediate it, and the physiological and biochemical mechanisms of its action. Other behavioral effects that analgesia-producing stimulation might also produce have not been studied extensively. Such observations that are available in the literature were usually made in passing, while testing the analgesic effects of the stimulation. These observations suggest that stimulation that produces analgesia has little or no effect on other behavioral processes. Eating and drinking were sometimes affected (Mayer et al., 1971; Soper, 1976), but reactivity to sensory stimuli other than noxious ones is described as normal in general (Balagura \& Ralph, 1973; Mayer et al., 1971; Oliveras et al., 1974; Reynolds, 1969; Soper, 1976), except in some cases during the stimulation itself (Morrow \& Casey, 1976; Rhodes \& Liebeskind, 1978). Recently, however, Thomas (1984) has presented a detailed description of a generalized behavioral suppression that follows brainstem stimulation in rats. Although this effect was often associated with analgesia, it was also obtained independently. Kuroki (1958) described an apparently similar phenomenon in cats, but did not investigate its association with analgesia.

The one behavioral effect of analgesia-producing stimulation that has been studied systematically is its association with positive reinforcement. Some workers (Mayer et al., 1971; Rose, 1974) found a positive relation between 
analgesia and positive reinforcement, but these processes can be dissociated (see, also, Balagura \& Ralph, 1973; Carr \& Coons, 1982; Mayer \& Liebeskind, 1974; Sandberg \& Segal, 1978; Segal \& Sandberg, 1977; Soper, 1976). Some sites at which analgesia can be produced do not support self-stimulation, and many that support selfstimulation cannot be stimulated to produce analgesia.

Recent electrophysiological data are relevant to the question of how selective the effects of analgesiaproducing stimulation are. Several studies have tested the effects of stimulation in analgesia-producing sites of the brainstem on unit activity of cells in the dorsal horn of the spinal cord and homologous portions of the spinal trigeminal nucleus. Cells that respond to noxious stimuli show inhibition under these experimental conditions (see, e.g., Beall, Martin, Applebaum, \& Willis, 1976; Carstens, 1982; Gebhart, Sandkühler, Thalhammer, \& Zimmerman, 1983, 1984; Gerhart, Wilcox, Chung, \& Willis, 1981; Gerhart, Yezierski, Wilcox, \& Willis, 1984; Liebeskind et al., 1973; Oliveras et al., 1974; Sessle, Hu, Dubner, \& Lucier, 1981; see Willis, 1982, for a review), but the response of wide dynamic range cells to nonnoxious stimuli is also inhibited. Several recent studies have also demonstrated such inhibitory effects on nonnociceptive units, including primary afferents (Martin, Haber, \& Willis, 1979) and units in the spinal dorsal horn (Belcher, Ryall, \& Schaffner, 1978; Gray \& Dostrovsky, 1983; McCreery, Bloedel, \& Hames, 1979), the trigeminal nucleus caudalis (Dostrovsky, 1980; Dostrovsky, Shah, \& Gray, 1983), and the ventrobasal thalamus (Schieppati \& Gritti, 1983). Brainstem stimulation appears to be less effective in inhibiting responses to nonnoxious stimuli in either low-threshold cells or wide-dynamicrange cells than in inhibiting responses to noxious stimuli (Gebhart et al., 1983; Liebeskind et al., 1973; Oliveras et al., 1974; Sessle et al., 1981). Willis (1982) concludes that "the inhibition appears to be preferentially directed at the responses to $A \delta$ and $C$ fibers and less powerful on the responses to $A \alpha$ and $\beta$ fibers ... Although this would lead to the expectation that there should be a more powerful inhibition of the responses of STT [spinothalamic tract] cells to noxious than to innocuous stimuli, this is only rarely the case." (p. 95). Cells in the dorsal column nuclei are rarely affected by brainstem stimulation (Gerhart et al., 1981). These electrophysiological studies suggest that at least some kinds of analgesia-producing brainstem stimulation can affect somatosensory perception.

The purpose of the present research was to test whether analgesia-producing stimulation had behavioral effects other than analgesia. Specifically, the effect of such stimulation on rat's tactile discrimination performance was assessed. Most, but not all, rats that showed analgesia following stimulation in PAG had also shown disruption of tactile discrimination following such stimulation.

\section{METHOD}

\section{Subjects}

Usable data were obtained from 19 adult female albino rats derived from the Sprague-Dawley strain (Harlan Industries, In- dianapolis). They weighed between 182 and $345 \mathrm{~g}$ at the time of implantation and were individually housed on a $12: 12 \mathrm{~h}$ light-dark schedule with water available at all times. Data from an additional six rats were excluded because of incomplete testing and technical difficulties.

\section{Apparatus}

Tactile discrimination was tested in a sheet-metal-lined T-maze similar to that used in several other studies in this laboratory (e.g., Finger \& Frommer, 1968; Frommer, 1981; Frommer \& CamposDomingo, 1985). It had 45-cm-long arms and a $30-\mathrm{cm}-$ long stem, which served as the start area. The alleys were $7.5 \mathrm{~cm}$ wide and $27 \mathrm{~cm}$ high and were open at the top to permit free movement of the rat with the stimulating cable attached. A sliding door separated the stem from the arms and activated an electronic stopwatch when opened. The floors of the two arms were covered with movable aluminum plates, which served as the tactile discriminanda. One of the two plates was always smooth; the other was one of a standard series incised with grooves of progressively decreasing dimensions. The roughest had 2-mm-deep V-shaped grooves that were $6.5 \mathrm{~mm}$ apart and intersected to form $3 \times 4 \mathrm{~mm}$ diamond-shaped elevations. The finest used in this experiment had parallel grooves, $0.5 \mathrm{~mm}$ deep, $1.6 \mathrm{~mm}$ wide, and separated by $4.6 \mathrm{~mm}$, which ran the length of the plate. Electrical stimulation was generated by Tektronix 160 series pulse and waveform generators which drove a constant current source through isolation transformers.

\section{Surgery}

The rats were pretreated with atropine methyl bromide ( 2 to $5 \mathrm{mg}$, ip) and were anesthetized with a mixture of pentobarbital, chloral hydrate, and $\mathrm{Mg}$ ion (Chloropent, Fort Dodge Laboratories, $2.5 \mathrm{ml} / \mathrm{kg}$, ip). They were blinded by enucleation to abolish visual cues. This procedure is justified because the albino rats depend little on vision for their normal activities, and the procedure has no detectable effect on normal behavior. When enucleation is done under ether anesthesia the rats eat, groom, explore, and are otherwise normal within $1 / 2 \mathrm{~h}$ afterwards.

The rat was then mounted in a stereotaxic frame (Frommer, 1971) for implantation of the electrodes used to stimulate brainstem sites and to deliver brief, subcutaneous noxious stimuli. Bipolar electrodes were made by twisting together two strands of 0.18 -mm-diam Teflon-insulated stainless steel wire, which was bared only in cross section. The electrodes implanted in the brain had a tip separation of about $0.5 \mathrm{~mm}$. Those implanted subcutaneously had tips separated by $2-4 \mathrm{~mm}$. Wire coils for delivering noxious heat stimuli were made of 9-cm-long pieces of the Teflon-insulated wire wrapped 10 times around 20 -ga hypodermic tubing. They had a resistance of about $3 \Omega$. All leads from the rat were terminated with goldplated subminiature contacts (Amphenol 220-P02).

The first 16 rats had a bipolar stimulating electrode and a heating coil implanted subcutaneously in the distribution of the maxillary division of the left and right trigeminal nerves, respectively. The remaining three rats had heating coils implanted bilaterally. Two bipolar electrodes were implanted in the brainstem. With one exception only electrodes aimed at the midbrain PAG were tested. These electrodes were implanted on the midline 5.7-6.8 mm caudal and 5.5-6.5 mm ventral to bregma (top of skull horizontal) or, in one rat, $5.0 \mathrm{~mm}$ caudal and $6.5 \mathrm{~mm}$ ventral to bregma (skull tilted $13^{\circ}$ downwards in the DeGroot, 1959, coordinate system). One rat was tested with an electrode aimed at the medullary midline raphe nuclear complex (10.4 mm caudal and $11.7 \mathrm{~mm}$ ventral to bregma, skull tilted $13^{\circ}$ downwards). The contacts terminating the implanted leads were cemented (Grip, L. D. Caulk Co.) to the skull between two acrylic strips, which protected the contacts from being bent. The skin was sutured snugly around the cement, and a mixture of penicillin $\mathrm{G}$ procaine and penicillin $\mathrm{G}$ benzathine (Flo-Cillin, Bristol) was administered prophylactically.

\section{Procedure}

The rats were placed on a $22-\mathrm{h}$ food-deprivation schedule and 
were trained 5-6 days/week on a series of tactile discriminations in the T-maze. The procedures were the same as those used in previous studies (e.g., Finger \& Frommer, 1968; Frommer, 1981), except that six trials/session were given instead of five, the trials were massed instead of spaced, with the rat being placed in a holding chamber between trials, latency as well as correctness of the response was recorded, and only the first four discriminanda from the standard series were used. The rats had to discriminate between a smooth and a grooved aluminum plate to gain access to wet mash for about $15 \mathrm{sec}$. To control for odor cues, the maze was wiped with soapy water after each trial, and mash was placed at the end of both arms but was accessible only at the end of the correct arm. The position of the correct floor plate was varied according to rules proposed by Fellows (1967). Training began with the coarsest plate and progressed to plates with successively finer grooves when a rat reached a criterion of 17 out of 18 correct in 3 consecutive days. The rats were overtrained for several weeks on the last task (on which the effects of the brain stimulation were to be tested), were implanted with the stimulating electrodes, and were retrained to criterion. Retraining required a median of 8 days, including 3 days of criterion.

After the rats were implanted, the effectiveness of brainstem stimulation in producing analgesia was assessed, primarily by means of a procedure modified from that of Rosenfeld, Broton, and Clavier (1978). At intervals of at least $10 \mathrm{~min}, \mathrm{a} 0.5$ - or 0.6 -A current $(0.7$ to $1.1 \mathrm{~W}$ ) was passed through the implanted heating coil until the rat made a face-wiping movement. After baseline latency (usually 3 to $5 \mathrm{sec}$ ) of this response was established for a rat, 5-sec trains of stimulation $(50-\mathrm{Hz}, 0.2-\mathrm{msec}$ bipolar pulse pairs) were delivered through the brainstem electrode about $30 \mathrm{sec}$ before the coil was scheduled to be heated. The brain stimulation current started at 50 $\mu \mathrm{A}$ and was increased on successive trials until the rat showed a clear increase in latency of the face-wiping response or a very strong reaction to the brain stimulation itself, or until the stimulating current reached $700 \mu \mathrm{A}$. Brainstem stimulation sessions were separated by at least 3 days to decrease the development of tolerance (Mayer $\&$ Hayes, 1975). The intensities used in the tactile discrimination tests were reevaluated for their analgesic effect on at least one subsequent session for all but two rats.

A secondary measure of analgesia used the reaction of the rat to single shocks of increasing intensity through the subcutaneous electrode as the test response. Analgesia-producing brainstem stimulation attenuated the amplitude and changed the configuration of the reaction to the shock. However, the baseline reaction to the subcutaneous shocks progressively declined, so the effectiveness of the brainstem stimulation in inducing analgesia was often difficult to assess. Twelve rats were also tested for orienting responses to gentle touch with a wire probe before and approximately $1 \mathrm{~min}$ after analgesia-producing stimulation in the analgesia test.

When an appropriate intensity for brainstem stimulation was established, it was delivered to the rat before the second, third, or fourth trial of tactile discrimination test sessions separated by at least 3 days. A single 5-sec train of stimulation was delivered while the rat was in the holding chamber about $15 \mathrm{sec}$ before it was placed in the start area of the T-maze. These trials formed the 15-sec delay condition and measured effects of the brainstem stimulation that outlasted the stimulation itself by at least $15 \mathrm{sec}$. To test brainstem stimulation directly related to the tactile discrimination, 15 of the rats were later stimulated while in the maze at the start of a tactile discrimination trial. These trials formed the 0 -sec delay condition and measured the more immediate effects of the stimulation. In this portion of the experiment, the brainstem stimulation was delivered once during each discrimination training session.

After the behavioral data had been collected, the rats were deeply anesthetized and perfused through the heart with $0.9 \%$ saline followed by $10 \%$ formalin in $0.9 \%$ saline. After fixation, frozen sections were cut at $40 \mu$, stained with cresyl violet, and mounted. Drawings were made of the sections showing the apparent maxi- mum electrode penetration by projecting the sections onto paper with a microprojector.

\section{RESULTS}

Twelve of the rats met at least one of two criteria for induction of analgesia by brainstem stimulation. Eight met both. The two criteria were: (1) $>20 \%$ increase in mean latency of the face-wiping response, and (2) a majority of tests showing a latency increase $>3$ standard deviations above the mean of the baseline latency. Of these 12 rats, 8 had stimulating electrodes in the dorsal two-thirds of PAG. These 8 form the Analgesia-PAG group. Four of the 7 rats in this group that were tested showed less brisk orienting responses to light touch following analgesia tests. The remaining 4 rats showing analgesia had electrodes in the dorsal raphe or ventral PAG, caudal midline thalamic nuclei, medulla dorsolateral to the medullary raphe nuclear complex, or tectum dorsal to PAG. These 4 rats form the Analgesia- $\overline{P A G}$ group. One of the 2 rats in this group that were tested showed less brisk orienting responses to light touch following analgesia tests. Of the 7 rats that failed to meet either criterion for analgesia following brainstem stimulation, 4 had electrodes in dorsal raphe or ventral PAG, 2 had electrodes in the tectum or dorsal margin of PAG, and 1 had its electrode in the caudal midline thalamic nuclei. These rats form the No-Analgesia group. None of the 3 rats in this group that were tested showed less brisk orienting responses to light touch following analgesia tests. Figure 1 presents drawings of sections showing the location of the electrode tips in all 19 rats divided into these three groups.

Table 1 presents the mean percent errors for these three groups on the trial preceding the brain stimulation (PRE), the trial immediately following stimulation (TEST), and the subsequent trial (SUBS) for the 15-sec-delay and 0 -sec-delay conditions of the tactile discrimination. Stimulation increased mean percent errors on the TEST trials for the Analgesia-PAG group in the 15-sec-delay condition and for both analgesia groups in the 0-sec-delay condition. This conclusion is supported by ANOVAs, which show significant main effects for trials $[\mathrm{F}(2,32)=8.754$, $\mathrm{p}<.01$, and $\mathrm{F}(2,24)=19.779, \mathrm{p}<.01$, respectively $]$ and significant trials $\times$ groups interactions $[\mathrm{F}(4,32)=$ $4.661, \mathrm{p}<.01$, and $\mathrm{F}(4,24)=3.298$, $\mathrm{p}<.05$, respectively]. Mann-Whitney U tests on the TEST trials confirm this conclusion. In the 15-sec-delay condition, the Analgesia-PAG group differed significantly from the Analgesia- $\overline{\mathrm{PAG}}$ and the No-Analgesia groups $(\mathrm{p}<.002$ and .05 , respectively), which did not differ from each other. In the 0 -sec-delay condition, the two analgesia groups differed significantly from the No-Analgesia group ( $p<.002$ and .003 , respectively) but did not differ from each other.

The mean latency data presented in Table 2 also show the effect of analgesia-producing stimulation on tactile discrimination performance in the 15 -sec-delay condition. 


\section{Analgesia - PAG}

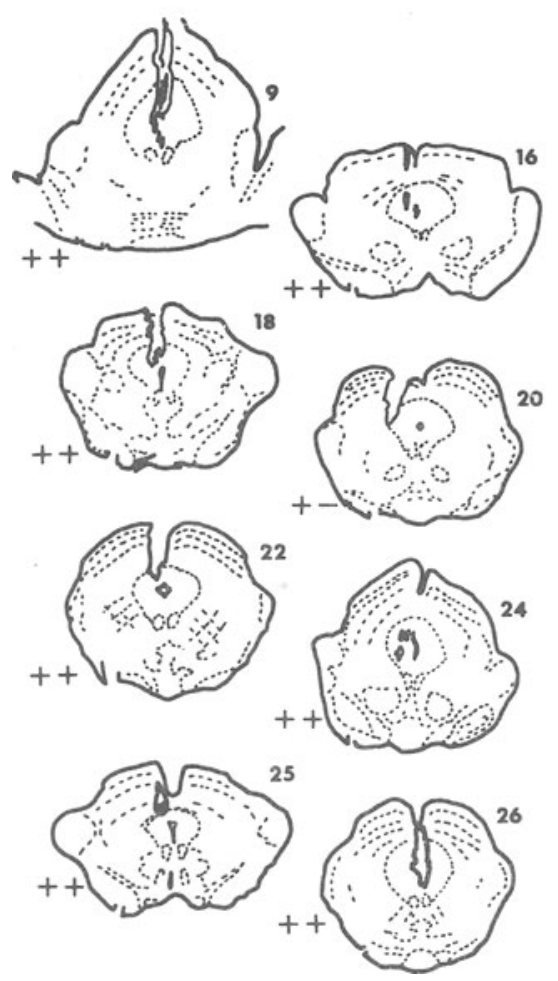

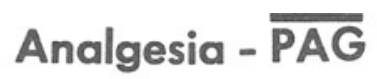
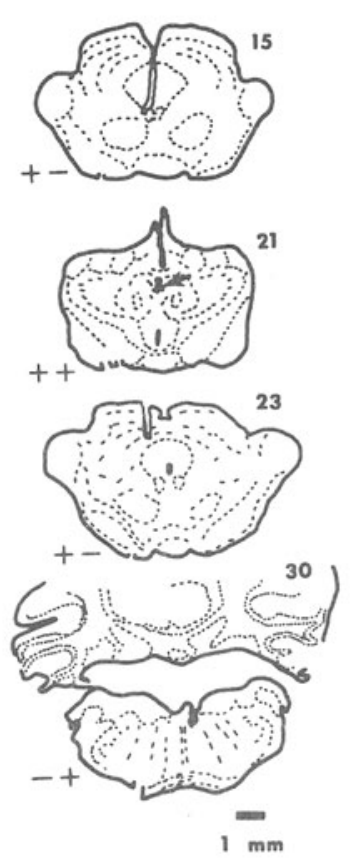

No Analgesia
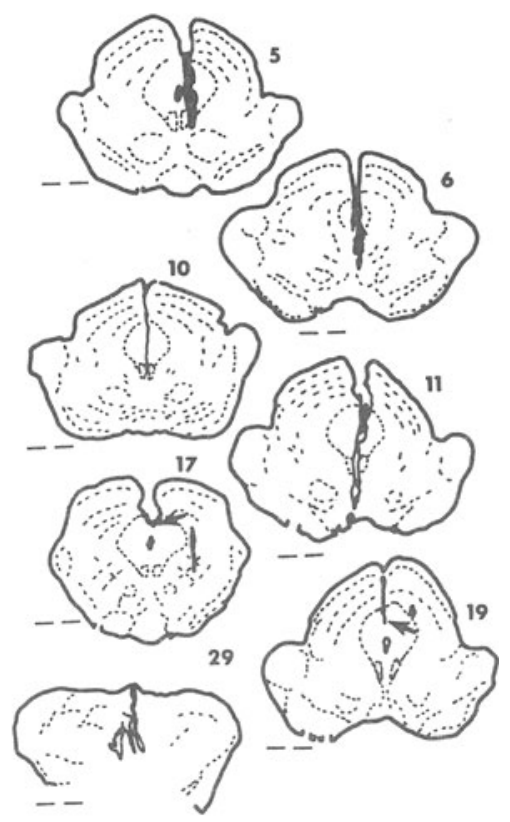

Figure 1. Tracings of cresyl-violet-stained sections showing apparent maximum penetration of stimulation electrode. Tracings are grouped according to electrodes in dorsal two-thirds of PAG capable of inducing analgesia (Analgesia-PAG), electrodes outside dorsal two-thirds of PAG capable of inducing analgesia (Analgesia- $\overline{\mathrm{PAG}}$ ), and electrodes not capable of inducing analgesia (No Analgesia). The $+s$ or $-s$ by each tracing represent the presence or absence of analgesia as measured by $>20 \%$ latency increase in face-wiping responses (left) and majority of face-wiping response latencies increased by $>3$ SD above mean baseline (right).

An ANOVA shows a significant main effect for trials $[F(2,32)=8.472, p<.01]$, but the group $\times$ trials interaction fails to reach significance, apparently because of two rats, one in each analgesia group, which were ex-

Table 1

Mean Percent Errors on Tactile Discrimination Trials

\begin{tabular}{lccccccc}
\hline & \multicolumn{3}{c}{ 15-Sec-Delay } & Trials & & \multicolumn{3}{c}{ 0-Sec-Delay } & Trials \\
\cline { 2 - 4 } \cline { 6 - 8 } \multicolumn{1}{c}{ Group } & PRE & TEST & SUBS & & PRE & TEST & SUBS \\
\hline Analgesia-PAG & 0.6 & 28.8 & 6.2 & & 4.2 & 37.7 & 4.8 \\
Analgesia-PAG & 5.0 & 3.0 & 4.2 & & 0.0 & 49.0 & 0.0 \\
No Analgesia & 1.1 & 11.1 & 4.0 & & 2.2 & 9.3 & 2.0 \\
\hline
\end{tabular}

Note: $P R E=$ trial preceding stimulation; $T E S T=$ trial immediately following stimulation; SUBS = subsequent trial.

Table 2

Mean Latency in Seconds of Tactile Discrimination Responses

\begin{tabular}{|c|c|c|c|c|c|c|}
\hline \multirow[b]{2}{*}{ Group } & \multicolumn{3}{|c|}{ 15-Sec-Delay Trials } & \multicolumn{3}{|c|}{ 0-Sec-Delay Trials } \\
\hline & PRE & TEST & SUBS & PRE & TEST & SUBS \\
\hline Analgesia-PAG & 1.93 & 6.20 & 2.51 & 2.63 & 11.62 & 5.02 \\
\hline Analgesia-PAG & 1.88 & 9.62 & & 3.13 & & 2.30 \\
\hline No Analgesia & 1.37 & 1.47 & 1.39 & 3.05 & 10.83 & 2.85 \\
\hline
\end{tabular}

Note: $P R E=$ trial preceding stimulation; $T E S T=$ trial immediately following stimulation; SUBS = subsequent trial. tremely deviant in the predicted direction. Mann-Whitney U tests between the groups on the TEST trials show that the Analgesia-PAG and the Analgesia- $\overline{\mathrm{PAG}}$ groups differed significantly from the No-Analgesia group $(\mathrm{p}<$ .001 and .005 , respectively) but did not differ from each other. In the 0-delay-condition all three groups showed about equally increased latencies on the POST trials, a reasonable consequence of the nonspecific effects of brainstem stimulation. The ANOVA shows a significant main effect only for trials $[\mathrm{F}(2,24)=11.334, \mathrm{p}<.01]$.

The group differences in performance on TEST trials can be seen in the performance of individual animals. In the 15-sec-delay condition, four of the rats in the Analgesia-PAG group showed significantly elevated errors and seven showed significantly elevated latencies on TEST trials as compared with the PRE and SUBS trials (Cochran $\mathrm{Q}$ tests, $\mathrm{Q}>6.50, \mathrm{p}<.05$; Friedman tests, $\left(\chi_{\mathrm{r}}{ }^{2}>7.00\right.$, $\mathrm{p}<.05)$. One rat from the Analgesia- $\overline{\mathrm{PAG}}$ group showed significantly increased latencies. None of the other rats showed these effects.

\section{DISCUSSION}

The rats in the present experiment were divided according to the effectiveness of brainstem stimulation in pro- 
ducing increased latency of the face-wiping response to subcutaneous heating and according to the anatomical location of the stimulating electrodes within or outside the dorsal two-thirds of PAG. The three groups formed this way, Analgesia-PAG, Analgesia-PAG, and No Analgesia, differed significantly in performance of a tactile discrimination on test trials immediately following brainstem stimulation. Performance of the rats showing analgesia was disturbed, especially when the stimulating electrodes were in the dorsal portion of PAG. Performance of rats not showing analgesia was unaffected, except in the 0 -sec-delay condition, where latency was elevated for all three groups, an effect that presumably reflects the varied direct effects of the stimulation.

The apparent functional differentiation between dorsal PAG (Analgesia-PAG group) and ventral PAG and the dorsal raphe nucleus ventral to it (most of No Analgesia group) is parallel to the differentiation obtained by Liebeskind and his co-workers (Cannon, Prieto, Lee, \& Liebeskind, 1982; Prieto, Cannon, \& Liebeskind, 1983). They found that stimulation in dorsal PAG produced increased tail-flick latencies that outlasted the stimulation and were unaffected by naloxone or by lesions in medullary nucleus raphe magnus. In contrast, stimulation more ventrally in the dorsal raphe nucleus produced increases in tail-flick latency that were less likely to outlast the stimulation and were reduced both by naloxone and by lesions in the nucleus raphe magnus.

There are several possible processes the analgesiaproducing stimulation may have affected to disturb tactile discrimination performance. Somatosensory discriminative capacity may have been depressed by modifying transmission in somatosensory afferent pathways. Electrophysiological data show that stimulation in midbrain structures in which analgesia can be induced also can modulate responsiveness of primary afferent terminals (Martin et al., 1979), second-order neurons (Belcher et al., 1978; Dostrovsky et al., 1983; Gray \& Dostrovsky, 1983; McCreery et al., 1979), and ventrobasal neurons (Schieppati \& Gritti, 1983) that respond to nonnoxious stimuli. Thus, a possible mechanism for sensory disturbance exists.

However, several alternative explanations must also be considered. First, the analgesia-producing stimulation may have lowered drive, disturbed motor function, or produced some other generalized depressive effect. Stimulation of analgesia-producing sites in the brainstem also produces a generalized suppression of behavior (Thomas, 1984) and often produces strong motor reactions, but these effects can also be found independently of analgesia effects (see, also, Kuroki, 1958). Depressed orienting responses following analgesia tests suggests that some process that produces generalized depression was associated with analgesia in the present experiment. This generalized depression in performance probably contributed to the observed increases in latency, but it may not account for the increases in errors on tactile discrimination trials immediately following analgesia-producing stimulation. For example, the stimulation may have decreased drive level, which would account for increases in latency but not in errors. Variation in drive level over a wide range affects speed or vigor of responding but not the frequency of errors on sensory discriminations (Dinsmoor, 1952; Eisman, Asimow, \& Maltzman, 1956; Miles, 1959; Warren \& Hall, 1956). A motor interpretation of the data is similarly inadequate. The brain stimulation usually produced motor effects, some of which were directed consistently toward one side or the other. However, none of the rats that made more than one error on the TEST trials made them all to the same side, and several rats that showed no laterally directed response to the stimulation increased errors after stimulation. Furthermore, errors made during medial lemniscal stimulation were not systematically associated with the direction of movement elicited by the stimulation (Frommer \& CamposDomingo, 1985).

Second, the stimulation may have induced an internal state, such as arousal, positive hedonic effects, or aversive effects, which may have served as a distracter. However, strong behavioral reactions to stimulation that are suggestive of aversive effects of brainstem stimulation are associated with a generalized decrement in performance on all trials, not just on those with test stimulation (Frommer \& Campos-Domingo, 1985), and arousal from midbrain reticular stimulation facilitates performance of sensory discrimination (Fuster \& Uyeda, 1962; Hoyman \& Kelsey, 1977). By itself, intense arousal due to strong motor effects of midbrain stimulation has no effect on errors in tactile discriminative performance during stimulation (Frommer \& Campos-Domingo, 1985). Brain stimulation that produced a positive hedonic effect, as described by subjective report, depressed performance on a visual detection task in a single human subject (Galbraith \& Heath, 1970). The analgesia-producing stimulation in the present experiment could have induced an analogous effect in the rats, because analgesia-producing stimulation may also produce positive reinforcing effects (Mayer et al., 1971; Rose, 1974). But for such an effect to account for the disruption, it would have had to outlast the stimulation by $15 \mathrm{sec}$ or more and survive the process of transferring the rat from the holding container to the maze.

Third, the disruption of discriminative performance may have reflected a state-dependent process (Overton, 1971). This explanation requires that performance improve over repeated trials. No evidence for such improvement appears in the data, although the number of trials (7 to 20) may not have been enough to reveal such a trend.

Finally, the stimulation may have produced its effects on tactile discrimination by activating a system that is separate from, but spatially contiguous to or overlapping with, the analgesia-producing system. Thomas's (1984) observations on behavioral suppression following brainstem stimulation suggests such a system. If the stimulation effects are specific to the somatosensory system, one possible candidate is the spinotectal tract of the somatosensory system, which travels close to the location of ef- 
fective stimulation. Stimulation in various sensory pathways, including medial lemniscus in midbrain, has been found to disrupt sensory discrimination or perception (Frommer \& Campos-Domingo, 1985). However, in the present experiment, electrodes dorsal to PAG and as close or closer to the spinotectal tract did not disturb tactile discrimination (e.g., Rats 17 and 19). Furthermore, the rats made their choices at least a few seconds after the brainstem stimulation terminated. In previous studies that showed an effect of electrical stimulation in sensory pathways on sensory discrimination, the discrimination was made during the stimulation.

While the data may not permit unambiguous selection among alternative interpretations, they do demonstrate that analgesia-producing stimulation has significant behavioral effects other than reduction of responsiveness to noxious stimuli and probably other than positive reinforcement. Other data from this laboratory support this interpretation. Five seconds of analgesia-producing brainstem stimulation depressed drinking for several minutes in rats deprived of water for about $24 \mathrm{~h}$. Stimulation that did not produce analgesia (or strong aversive reactions) produced only brief disruption of drinking (Frommer, unpublished observations). These findings, together with those from other behavioral studies of brainstem stimulation (e.g., Bovier, Broekkamp, \& Lloyd, 1982; Kiser, Brown, Sanghera, \& German, 1980; Kuroki, 1958; Nakao, Yoshida, \& Sasaki, 1968; Skultety, 1963; Thomas, 1984), indicate that a fuller behavioral analysis of the effects of electrical activation of analgesiaproducing systems is warranted.

\section{REFERENCES}

Balagura, A., \& RAlPH, T. (1973). The analgesic effect of electrical stimulation of the diencephalon and mesencephalon. Brain Research, 60, 369-379.

Basbaum, A. I., \& Fields, H. L. (1978). Endogenous pain control mechanisms: Review and hypothesis. Annals of Neurology, 4, 451-462.

Beall, J. E., Martin, R. F., Applebaum, A. E., \& Willis, W. D. (1976). Inhibition of primate spinothalamic tract neurons by stimulation in the region of the nucleus raphe magnus. Brain Research, 114, 328-333.

Belcher, G., Ryall, R. W., \& SchaffNer, R. (1978). The differential effects of 5-hydroxy tryptamine, noradrenaline and raphe stimulation on nociceptive and non-nociceptive dorsal horn interneurons in the cat. Brain Research, 151, 307-321.

Bovier, P., BroekKamp, C. L., \& Lloyd, K. G. (1982). Enhancing GABAergic transmission reverses the aversive state in rats induced by electrical stimulation of the periaqueductal grey region. Brain Research, 248, 313-320.

Cannon, J. T., Prieto, G. J., Lee, A., \& Liebeskind, J. C. (1982). Evidence for opioid and non-opioid forms of stimulation-produced analgesia in the rat. Brain Research, 243, 315-321.

CARR, K. D., \& CoONS, E. E. (1982). Rats self-administer nonrewarding brain stimulation to ameliorate aversion. Science, 215, 1516-1517.

CARSTENS, E. (1982). Inhibition of spinal dorsal horn neuronal responses to noxious skin heating by medial hypothalamic stimulation in the cat. Journal of Neurophysiology, 48, 808-822.

Cox, V. C., \& VAlenstein, E. S. (1965). Attenuation of aversive properties of peripheral shock by hypothalamic stimulation. Science, 149, 323-325.
DEGroot, J. (1959). The rat forebrain in stereotaxic coordinates. Verhandelingen der Koninklijke Nederlandse Akademie van Wetenschappen, Afd. Natuurkunde, 52, 1-40.

DinSMOOR, J. A. (1952). The effect of hunger on discriminated responding. Journal of Abnormal and Social Psychology, 47, 67-72.

Dostrovsky, J. O. (1980). Raphe and periaqueductal gray induced suppression of non-nociceptive neuronal responses in the dorsal column nuclei and trigeminal subnucleus candalis. Brain Research, 200, 184-189.

Dostrovsky, J. O., ShaH, Y., \& Gray, B. G. (1983). Descending inhibitory influences from periaqueductal gray, nucleus raphe magnus, and adjacent reticular formation. II. Effects on medullary dorsal horn nociceptive and nonnociceptive neurons. Journal of Neurophysiology, 49, 948-960.

Eisman, E., Asimow, A., \& Maltzman, I. (1956). Habit strength as a function of drive in a brightness discrimination problem. Journal of Experimental Psychology, 52, 58-64.

Fellows, B. J. (1967). Chance stimulus sequences for discrimination tasks. Psychological Bulletin, 67, 87-92.

Finger, S., \& Frommer, G. P. (1968). Effects of cortical lesions on tactile discriminations graded in difficulty. Life Sciences, 7, 897-904.

Frommer, G. P. (1971). Modified nontraumatic headholder. Behavior Research Methods \& Instrumentation, 3, 225-226.

Frommer, G. P. (1981). Tactile discrimination and somatosensory evoked responses following midbrain lesions in cats and rats. Experimental Neurology, 73, 775-800.

Frommer, G. P., \& CAMPOS-Domingo, M. P. (1985). Disruption of tactile discrimination in rats by bilateral stimulation of midbrain lemniscal pathways. Physiology \& Behavior, 34, 205-211.

Fuster, J. M., \& UYEDA, A. A. (1962). Facilitation of tachistoscope performance by stimulating midbrain tegmental points in the monkey. Experimental Neurology, 6, 384-406.

Galbraith, G. C., \& Heath, R. G. (1970). Backward visual masking during direct brain stimulation in man. Vision Research, 10, 911-915.

Gebhart, G. F., SAndkühler, J., Thalhammer, J. G., \& ZimmerMAN, M. (1983). Quantitative comparison of inhibition in spinal cord of nociceptive information by stimulation in periaqueductal gray or nucleus raphe magnus of the cat. Journal of Neurophysiology, $\mathbf{5 0}$, 1433-1445.

Gebhart, G. F., Sandkühler, J., Thalhammer, J. G., \& ZimmerMAN, M. (1984). Inhibition in spinal cord of nociceptive information by electrical stimulation and morphine microinjection at identical sites in midbrain of the cat. Journal of Neurophysiology, 51, 75-89.

Gerhart, K. D., Wilcox, T. K., Chung, J. M., \& Willis, W. D. (1981). Inhibition of nociceptive and nonnociceptive responses of primate spinothalamic cells by stimulation in medial brain stem. Journal of Neurophysiology, 45, 121-136.

Gerhart, K. D., Yezierski, R. P., Wilcox, T. K., \& Willis, W. D. (1984). Inhibition of primate spinothalamic tract neurons by stimulation in periaqueductal gray or adjacent midbrain reticular formation. Journal of Neurophysiology, 51, 450-466.

Gray, B. G., \& Dostrovsky, J. P. (1983). Descending inhibitory influences from periaqueductal gray, nucleus raphe magnus, and adjacent reticular formation. I. Effects on lumbar spinal cord nociceptive and nonnociceptive neurons. Journal of Neurophysiology, 49, 932-947.

Hosobuchi, Y., Adams, J. E., \& Linchitz, R. (1977). Pain relief by electrical stimulation of the central gray matter in humans and its reversal by naloxone. Science, 197, 183-186.

Hoyman, L., \& Kelsey, J. E. (1977). Facilitation of flicker discriminability by electrical stimulation of the mesencephalic reticular formation of the rat. Journal of Comparative and Physiological Psychology, 91, 951-961.

Kiser, R. S., Brown, C. A., Sanghera, M. K., \& German, D. C. (1980). Dorsal raphe nucleus stimulation reduces centrally-elicited fearlike behavior. Brain Research, 191, 265-272.

KUROKI, T. (1958). Arrest reaction elicited from the brain stem. Folia Psychiatrica et Neurologica Japonica, 12, 317-339.

Liebeskind, J. C., Guilbaud, G., Besson, J. M., \& Oliveras, J. L. (1973). Analgesia from electrical stimulation of the periaqueductal 
gray matter in the cat: Behavioral observations and inhibitory effects on spinal cord interneurons. Brain Research, 50, 441-446.

Martin, R. F., Haber, L. H., \& Willis, W. D. (1979). Primary afferent depolarization of identified cutaneous fibers following stimulation in medial brain stem. Journal of Neurophysiology, 42, 779-790.

MAYER, D. J., \& HAYES, R. L. (1975). Stimulation produced analgesia: Development of tolerance and cross-tolerance to morphine. Science, 188, 941-943.

MAYeR, D. J., \& Liebeskind, J. C. (1974). Pain reduction by focal electrical stimulation of the brain: An anatomical and behavioral analysis. Brain Research, 68, 73-93.

Mayer, D. J., Wolfle, T. L., Akil, H., Carder, B., \& Liebeskind, J. C. (1971). Analgesia from electrical stimulation in the brainstem of the rat. Science, 174, 1351-1354.

McCreery, D. B., Bloedel, J. R., \& Hames, E. G. (1979). Effects of stimulating in raphe nuclei and in reticular formation on response of spinothalamic neurons to mechanical stimuli. Journal of Neurophysiology, 42, 166-182.

Miles, R. C. (1959). Discrimination in the squirrel monkey as a function of deprivation and problem difficulty. Journal of Experimental Psychology, 57, 15-19.

Morrow, T. J., \& CASEY, K. L. (1976). Analgesia produced by mesencephalic stimulation: Effect on bulboreticular neurons. In J. J. Bonica \& D. Albe-Fessard (Eds.), Advances in pain research and therapy (Vol. 1). New York: Raven.

NaKaO, H., Yoshida, M., \& SASAKI, T. (1968). Midbrain central gray and switch-off behavior in cats. Japanese Journal of Physiology, 18, 462-470.

Oliveras, J. L., Besson, J. M., Guilbaud, G., \& Liebeskind, J. C. (1974). Behavioral and electrophysical evidence of pain inhibition from midbrain stimulation in the cat. Experimental Brain Research, 20, 32-44.

Overton, D. A. (1971). State-dependent or "dissociated" learning produced with pentobarbital (revised with commentary). In J. A. Harvey (Ed.), Behavioral analysis of drug action. Research and commentary (pp. 58-83). Glenview, IL: Scott, Foresman.

Prieto, G. J., Cannon, J. T., \& Liebeskind, J. C. (1983). N. raphe magnus lesions disrupt stimulation-produced analgesia from ventral but not dorsal midbrain areas in the rat.Brain Research, 261, 53-57.

REYNOLDS, D. V. (1969). Surgery in the rat during electrical analgesia induced by focal stimulation. Science, 164, 444-445.

Rhodes, D. L., \& Liebeskind, J. C. (1978). Analgesia from rostral brain stem stimulation in the rat. Brain Research, 143, 521-532.
Richardson, D. E., \& AKIL, H. (1977). Pain reduction by electrical brain stimulation in man. Part 2: Chronic self-administration in the periventricular gray matter. Journal of Neurosurgery, 47, 184-194.

Rose, M. D. (1974). Pain-reducing properties of rewarding electrical brain stimulation in the rat. Journal of Comparative and Physiological Psychology, 87, 607-617.

Rosenfeld, J. P., Broton, J. G., \& Clavier, R. M. (1978). A reliable, facial nociception device for unrestrained, awake animals: Effects of morphine and trigeminal complex lesions. Physiology \& Behavior, 21, 287-290.

SANDBERG, D., \& SEgAL, M. (1978). Pharmacological analysis of analgesia and self-stimulation elicited by electrical stimulation of catecholamine nuclei in the rat brain. Brain Research, 152, 529-542.

SCHIEPPATI, M., \& GRITTI, I. (1983). Influence of locus ceruleus, raphe dorsalis, and periaqueductal gray matter on somatosensory-recipient thalamic nuclei. Experimental Neurology, 82, 698-705.

Segal, M., \& SANDBERG, D. (1977). Analgesia produced by electrical stimulation of catecholamine nuclei in the rat brain. Brain Research, 123, 369-372.

Sessle, B. J., Hu, J. W., Dubner, R., \& Lucier, G. E. (1981). Functional properties of neurons in cat trigeminal subnucleus caudalis (medullary dorsal horn). II. Modulation of responses to noxious and nonnoxious stimuli by periaqueductal gray, nucleus raphe magnus, cerebral cortex, and afferent influences, and effect of naloxone. Journal of Neurophysiology, 45, 193-207.

SkUlteTy, F. M. (1963). Stimulation of periaqueductal gray and hypothalamus. Archives of Neurology, 8, 608-620.

SOPER, W. Y. (1976). Effects of analgesic midbrain stimulation on reflex withdrawal and thermal escape in the rat. Journal of Comparative and Physiological Psychology, 90, 91-101.

Thомаs, A. J. (1984). Stimulation-produced analgesia and suppression of behavior in the rat. Physiological Psychology, 12, 285-292.

Warren, J. M., \& Hall, J. F. (1956). Discrimination of visual patterns as a function of motivation and frequency of reinforcement. Journal of Genetic Psychology, 88, 245-250.

WATKINS, L. R., \& MAYER, D. J. (1982). Organization of endogenous opiate and nonopiate pain control systems. Science, 216, 1185-1192.

WILLIS, W. D. (1982). Progress in sensory physiology: Vol. 3. Control of nociceptive transmission in the spinal cord. Berlin: Springer.

(Manuscript received February 12, 1985; revision accepted for publication July 6,1985 .) 